\title{
HUBUNGAN TINGKAT PENGETAHUAN DENGAN APLIKASI PENGISIAN PARTOGRAF OLEH MAHASISWI TINGKAT II PROGRAM STUDI DIII KEBIDANAN DI UNIVERSITAS MUHAMMADIYAH MATARAM
}

\author{
Uyunun Nudhira *, Indriyani Makmun, Cahaya Indah Lestari \\ "Kebidanan, Universitas Muhammadiyah Mataram, uyununnudhira14@gmail.com
}

INFO ARTIKEL
Riwayat Artikel:
Diterima: 15-03-2017
Disetujui: 12-06-2017

Kata Kunci:

Pengetahuan

Aplikasi Pengisian

Partograf

\begin{abstract}
ABSTRAK
Abstrak : Sebagian besar kematian ibu dapat dicegah dengan meningkatkan pengetahuan dan keterampilan petugas kesehatan dalam menolong persalinan, seperti penggunaan partograf. Tujuan penelitian adalah Menganalisa hubungan antara pengetahuan dengan aplikasi pengisian partograf oleh mahasiswi tingkat II program studi DIII kebidanan di Universitas Muhammadiyah Mataram. Desain penelitian ini menggunakan metode survey analitik. Pada penelitian ini menggunakan data primer yang berupa pengetahuan mahasiswa tentang partograf dengan aplikasi pengisian partograf dengan teknik observasi dengan alat bantu kuisioner, sedangkan data sekunder berupa data umum tentang tempat penelitian. Hasil penelitian menunjukkan bahwa secara umum tingkat pengetahuan responden adalah kurang $(5,4 \%)$ dan cukup $(27,0 \%)$ dan berada pada kategori tidak bisa $(40,5 \%)$ namun dari 37 responden $(67,7 \%)$ dengan pengetahuan baik memiliki kategori tidak bisa 5 orang. Uji korelasi chi square menyatakan nilai significancy-nya $p=0,001(p<0,05)$ sehingga Ho ditolak dan Ha diterima yang berarti ada korelasi yang signifikan antara kedua variabel. Berdasarkan hasil penelitian dapat disimpulkan bahwa ada hubungan antara pengetahuan mahasiswa tentang partograf dengan aplikasi pengisian partograf. Sehingga dapat digunakan sebagai bahan evaluasi dalam upaya meningkatkan pengetahuan dan aplikasi pengisian partograf oleh mahasiswa.
\end{abstract}

Abstract : Most of the maternal deaths can be prevented by improving the knowledge and skills of health workers in helping labor, such as the use of partograf. The purpose of the research was to analyze the relationship between knowledge with application partograf charging by student level II courses DIII kebidanan at Muhammadiyah University Mataram. The design of this study using the method of analytic survey. On the research of using primary data in the form of student knowledge about partograf with partograf application techniques of observation with questionnaire tools, while secondary data in the form of general data about the research. The results showed that in general the level of knowledge of respondents is less (5.4\%) and enough (27.0\%) and being on a category can't (40.5\%) but of the 37 respondents (67.7\%) with knowledge of good has a category can not 5 people. Chi square correlation test declared its significancy value $p=0.001(p<0.05)$ so Ho denied and Ha was accepted which means there is a significant correlation between the two variables. Based on the results of the study it can be concluded that there is a relationship between the knowledge of students about partograf with partograf filling applications. So it can be used as ingredients in an effort to improve the evaluation of the knowledge and application of filling partograf by students. 


\section{A. LATAR BELAKANG}

Menurut Survey Demografi dan Kesehatan Indonesia (SDKI) tahun 2012, angka kematian bayi (AKB) 32/1000 kelahiran hidup,sedangkan menurut profil kesehatan indonesia 2011 angka kematian ibu (AKI) di Indonesia adalah 349/100.00o kelahiran hidup, angka kematian ibu (AKI) di NTB adalah 320/100.000 kelahiran hidup, angka ini memang lebih tinggi dibandingkan dengan rata-rata AKI nasional, angka kematian bayi (AKB) 72/100o kelahiran hidup (SDKI, 2012).

Kejadian kematian ibu dan bayi sebagian besar terdapat di negara berkembang 100 kali lebih tinggi dibandingkan di negara maju. Salah satunya Indonesia, penyebab langsung kematian ibu sekitar 90\% disebabkan oleh perdarahan $28 \%$, eklampsia $24 \%$, infeksi $12 \%$, komplikasi puerperium $8 \%$, abortus $5 \%$, partus macet $5 \%$, trauma obstetri $5 \%$, emboli $3 \%$ (Anonim, 2012). Sedangkan kematian bayi disebabkan oleh masalah neonatal $48,2 \%$, diare $16 \%$, pneumonia $12,7 \%$, kelainan kongenital $6,7 \%$, meningitis $4,5 \%$, tetanus 1,9\% (Prasetyawati, 2011).

Pemahaman tentang persalinan sebagai kerangka multifaktor akan memberikan dasar terhadap pendekatan yang berpusat pada ibu dalam manajemen asuhan intranatal. Manajemen asuhan intranatal di komunitas merupakan suatu pendekatan yang berpusat kepada individu di masyarakat yang membutuhkan kemampuan analisis tinggi dan cepat terutama yang berhubungan dengan aspek sosial, nilai-nilai, dan budaya setempat. Dengan memberikan asuhan intranatal yang tepat dan sesuai standar, diharapkan dapat membantu menurunkan angka kematian ibu dan bayi (Yulifah \& Yuswanto, T.J.A, 2009).

Sebagian besar kematian ibu hamil, bersalin dan nifas dapat dicegah dengan penanganan yang adekuat. Salah satu upaya yang dapat dilakukan adalah meningkatkan pengetahuan dan keterampilan petugas kesehatan dalam menolong persalinan, seperti penggunaan partograf yaitu alat bantu untuk membuat keputusan klinik, memantau, mengevaluasi, dan menatalaksanakan persalinan. Partograf dapat digunakan untuk mendeteksi dini masalah dan penyulit dalam persalinan, sehingga dapat merencanakan tindakan mencegah terjadinya masalah, merujuk ibu dalam kondisi yang tepat. Instrumen ini merupakan salah satu komponen dari pemantauan dan penatalaksanaan proses persalinan secara lengkap (JNPK-KR, 2008).

Depkes RI, menyarankan dan mewajibkan bahwa semua penolong persalinan harus menggunakan partograf saat memberikan asuhan persalinan kepada ibu dan proses kelahiran bayinya. Tujuan penerapan partograf diharapkan bahwa angka kematian maternal dan perinatal dapat diturunkan dengan bermakna sehingga mampu menunjang sistem kesehatan menuju tingkat kesejahteraan masyarakat (JNPK-KR, 2008).

Dari hasil studi pendahuluan dengan 10 mahasiswi kebidanan tingkat II semester IV di Universitas Muhammadiyah Mataram, 5 orang (50\%) mengatakan mengetahui partograf dan cara pengisian partograf, 5 orang (50\%) mengatakan kurang mengetahui partograf dan bingung melakukan pengisian partograf.

Mahasiswi D3 kebidanan mendapatkan materi partograf di mata kuliah ASKEB II dimana mata kuliah ini didapatkan pada semester III kemudian mahasiswa akan diberikan kesempatan menerapkan ilmu / teori yang didapat pada saat praktek di rumah sakit, puskesmas, BPS, dan polindes, sehingga diharapkan mahasiswa sudah mampu melakukan observasi persalinan dengan menggunakan partograf. Diharapkan institusi pendidikan kesehatan mampu memberikan pemahaman dan pengajaran yang mudah dicerna dan dimengerti oleh mahasiswa penerima ilmu, sehingga mampu menciptakan dan melahirkan seorang bidan yang tanggap, tepat, cepat dalam memberikan asuhan khususnya pada asuhan pemantauan persalinan dengan menggunakan partograf.

Bertolak dari pemikiran di atas, maka peneliti tertarik untuk mengambil judul "Hubungan Pengetahuan dengan Aplikasi Pengisian Partograf Oleh Mahasiswi Tingkat II Kebidanan di Universitas Muhammadiyah Mataram ".

\section{B. METODE PENELITIAN}

Dalam penelitian ini metode penelitian yang digunakan adalah metode penelitian survei dengan pendekatan cross sectional yaitu penelitian dimana peneliti mempelajari hubungan variabel independent (pengetahuan) dengan variabel dependent (pengisian partograf) dengan melakukan pengukuran sesaat dan dinilai hanya satu kali saja. Dalam penelitian ini metode penelitian yang digunakan adalah korelasional (correlation study) merupakan penelitian atau penelaahan hubungan antara dua variabel pada suatu situasi atau sekelompok subjek. (Nursalam, 2011).

Penelitian ini dilakukan di tingkat II Prodi DIII Kebidanan Universitas Muhammadiyah Mataram pada tahun 2017. jumlah populasi yang ada sebanyak 60 orang. Teknik pengambilan sampel dalam penelitian ini adalah Non probability sampling yaitu Quota Sampling dengan cara menetapkan sejumlah anggota sample secara quotum atau jatah. yaitu dalam penelitian ini sebanyak 37 sample. Variabel bebas dalam penelitian ini adalah pengetahuan mahasiswa tentang partograf. Variabel terikat dalam penelitian ini adalah aplikasi mahasiswa terhadap pengisian partograf. Instrument penelitian menggunakan kuesioner yang dilakukan uji validitas dan reliabilitas.

Analisis data yang digunakan dalam penelitian ini meliputi dua hal yaitu, univariat menggambarkan tiaptiap variabel (variabel independen dan dependen) 
dengan menggunakan distribusi frekuensi dan proporsi, sehingga tergambar fenomena yang berhubungan dengan variabel yang diteliti. Bivariat dilakukan uji statistik dilakukan dengan menggunakan program Komputerized (SPSS versi 16.0) dan dilakukan uji chisquare yaitu, uji statistik yang digunakan untuk menguji signifikasi dua variabel (Arikunto, 2006).

\section{HASIL DAN PEMBAHASAN}

\section{HASIL}

\section{Distribusi Responden Berdasarkan Tingkat Pengetahuan}

TABEL 1

Distribusi Responden Berdasarkan Tingkat Pengetahuan Mahasiswa

\begin{tabular}{llcc}
\hline No & Tingkat & N & $\%$ \\
& Pengetahuan & & \\
\hline 1 & Baik & 25 & 67,6 \\
2 & Cukup & 10 & 27,0 \\
3 & Kurang & 2 & 5,4 \\
\hline Jumlah & & 37 & 100 \\
\hline
\end{tabular}

Berdasarkan tabel 4.1 distribusi responden berdasarkan tingkat pengetahuan mahasiswa tingkat II prodi DIII Kebidanan Universitas Muhammadiyah Mataram dapat dilihat dari 37 responden, mayoritas responden yakni 25 orang $(67,6 \%)$ berada pada kelompok tingkat pengetahuan baik, sedangkan yang paling sedikit responden 2 orang $(5,4 \%)$ berada pada kelompok tingkat pengetahuan kurang.

\section{Distribusi Responden Berdasarkan Apilkasi Pengisian Partograf}

TABEL 2

Distribusi Responden Berdasarkan Aplikasi Pengisian Partograf

\begin{tabular}{|c|c|c|c|}
\hline No & $\begin{array}{l}\text { Aplikasi } \\
\text { Pengisian } \\
\text { partograf }\end{array}$ & $\mathrm{N}$ & $\%$ \\
\hline 1 & Bisa & 22 & 59,5 \\
\hline \multirow[t]{2}{*}{2} & Tidak Bisa & 15 & 40,5 \\
\hline & Jumlah & 37 & 100 \\
\hline
\end{tabular}

responden berdasarkan aplikasi pengisian partograf oleh mahasiswa tingkat II program studi DIII Kebidanan di Universitas Muhammadiyah Mataram dapat dilihat bahwa sebagian besar responden 22 orang $(59,5 \%)$ berada pada kategori bisa melakukan pengisian partograf sedangkan yang 15 orang $(40,5 \%)$ berada pada kategori tidak bisa melakukan pengisian partograf.

\section{Hubungan Tingkat Pengetahuan dengan Aplikasi Pengisian Partograf} TABEL 3

Hubungan Tingkat Pengetahuan dengan Aplikasi Pengisian Partograf

\begin{tabular}{|c|c|c|c|c|}
\hline \multirow[t]{2}{*}{ No } & \multirow[t]{2}{*}{ Pengetahuan } & Aplikasi & Partograf & \multirow{2}{*}{$\begin{array}{l}\text { Jum } \\
\text { lah }\end{array}$} \\
\hline & & Bisa & Tidak Bisa & \\
\hline 1 & Baik & 20 & 5 & 25 \\
\hline 2 & Cukup & 2 & 8 & 10 \\
\hline \multirow[t]{2}{*}{3} & Kurang & o & 2 & 2 \\
\hline & Jumlah & 22 & 15 & 37 \\
\hline
\end{tabular}

hubungan pengetahuan dengan aplikasi pengisian partograf oleh mahasiswa tingkat II kebidanan di Universitas Muhammadiyah Mataram terlihat bahwa responden dengan pengetahuan baik yang bisa melakukan pengisian partograf sebanyak 20 orang, tidak bisa melakukan pengisian sebanyak 5 orang. Responden dengan pengetahuan cukup yang bisa melakukan pengisian partograf sebanyak 2 orang, tidak bisa melakukan pengisian sebanyak 8 orang. Responden dengan pengetahuan kurang yang bisa melakukan pengisian partograf tidak ada atau $\mathrm{o}$ orang, dan yang tidak bisa melakukan pengisian 2 orang.

Dari uji analisis statistik dengan uji Chi Square program SPSS versi 16,0 pada tingkat kesalahan $5 \%$ $(\alpha=0,05)$ menunjukkan bahwa nilai significancynya $\mathrm{p}=0,001(\mathrm{p}<0,05)$ sehingga Ho ditolak dan $\mathrm{Ha}$ diterima, dan dengan demikian dapat disimpulkan bahwa ada hubungan yang signifikan antara tingkat pengetahuan dengan aplikasi pengisian partograf.

\section{PEMBAHASAN}

Tingkat pegetahuan yang berbeda didasari oleh bagaimana penerimaan dan keaktifan mahasiswa dalam mempelajari materi yang diperoleh. Menurut (Mubarok, dkk 2007) Pengetahuan itu sendiri adalah merupakan hasil mengingat suatu hal, termasuk mengingat kembali kejadian yang pernah dialami baik sengaja maupun tidak sengaja dan ini terjadi setelah orang melakukan kontak atau pengamatan terhadap suatu objek tertentu. Sehingga dapat mengidentifikasikan bahwa sebagian besar Mahasiswa Tingkat II Prodi DIII kebidanan di Universitas Muhammadiyah Mataram telah memiliki tingkat pengetahuan yang baik dan telah menerima informasi pembelajaran tentang Askeb II persalinan, terutama tentang partograf.

Mahasiswa yang memiliki pengetahuan kurang disebabkan antara lain ketidak pahaman dengan materi terkait, ketidak hadiran pada kelas partograf, dan tidak aktif dalam mempelajari materi terkait, sehingga perlu mendapatkan pembinaan lagi tentang pengetahuannya terhadap partograf. Hal ini dapat menjadi suatu bahan evaluasi bahwa proses belajar-mengajar sebagian besar telah berlangsung dengan baik.

Banyak faktor yang mempengaruhi kemapuan mahasiswa dalam melakukan aplikasi pengisian partograf. Aplikasi pengisian yang baik dapat dipengaruhi oleh informasi yang diperoleh mahasiswa yang telah memadai, Pemahaman yang baik tentang partograf, dan karena telah sering mengaplikasikan 
partograf sebelumnya baik pada pelaksanaan tugas sehari-hari maupun pada saat melakukan praktik klinik kebidanan (PKK). Adapun mahasiswa yang belum mampu melakukan pengisian partograf dapat disebabkan informasi yang diperoleh terbatas, pemahaman yang masih kurang tentang partograf, serta jarang melakukan aplikasi pengisian partograf.

Kemampuan dalam pengisian partograf sangat penting dimiliki oleh tenaga kesehatan dalam melakukan pertolongan persalinan. Seperti dijelaskan dalam Depkes RI, menyarankan dan mewajibkan bahwa semua penolong persalinan harus menggunakan partograf saat memberikan asuhan persalinan kepada ibu dan proses kelahiran bayinya. Tujuan penerapan partograf diharapkan bahwa angka kematian maternal dan perinatal dapat diturunkan dengan bermakna sehingga mampu menunjang sistem kesehatan menuju tingkat kesejahteraan masyarakat (JNPK-KR, 2008). Hal ini disebabkan sebagian besar komplikasi yang banyak mengakibatkan terjadinya kematian maternal adalah pada saat persalinan dan masa nifas yang dapat dipantau dengan menggunakan partograf.

Pengetahuan seseorang mengenai suatu hal akan dilanjutkan dalam suatu kondisi nyata. Menurut Notoadmojo, 2012 yang menyatakan bahwa pengetahuan merupakan domain yang sangat penting untuk terbentuknya perilaku, pengetahuan dapat diperoleh dari pengalaman langsung maupun pengalaman orang lain. Adapun menurut mubarok, 2007 tingkat pengetahuan dibagi menjadi 6 tingkatan diantaranya adalah Tahu diartikan sebagai mengingat suatu materi yang telah dipelajari sebelumnya, mengingat kembali termasuk (recall), terhadap suatu yang spesifik dari seluruh bahan atau rangsangan yang diterima. Kemudian aplikasi adalah kemampuan untuk menggunakan materi yang telah dipelajari pada situasi atau kondisi nyata. Sehingga dapat disimpulkan bahwa seseorang yang memiliki tingkat pengetahuan baik lebih mampu dalam melakukan pengisian partograf, dibandingkan dengan yang memiliki tingkat pengetahuan cukup yang sebagian besar tidak bisa melakukan pengisian partograf dan yang memiliki tingkat pengetahuan kurang yang tidak mampu melakukan pengisian partograf. Dengan demikian antara pengetahuan dengan aplikasi sangat berkaitan erat satu sama lainnya.

\section{SIMPULAN DAN SARAN}

Dari uji analisis statistik dengan uji Chi Square program SPSS versi 16,0 pada tingkat kesalahan 5\% $(\alpha=0,05)$ menunjukkan bahwa nilai significancy-nya $p$ value $=0,001$ dimana nilai ini lebih kecil dari nilai taraf signifikan $0,05(\mathrm{p}<0,05)$ sehingga Hipotesis nol (Ho) ditolak dan Hipotesis alternatif (Ha) diterima, dan dengan demikian dapat disimpulkan bahwa ada hubungan yang signifikan antara tingkat pengetahuan dengan aplikasi pengisian partograf, semakin baik pengetahuannya maka mahasiswa akan semakin mengerti dalam aplikasi pengisian partograf.

Saran dalam penelitian ini dengan pengetahuan yang telah didapatkan, mahasiswa diharapkan mampu mengaplikasikan pengisian partograf. Agar dapat melakukan evaluasi terhadap ilmu yang didapatkan di pendidikan kebidanan. Sehingga dapat meningkatkan pengetahuan dan penerapan aplikasi pengisian partograf dalam setiap proses persalinan. Sehingga memberikan asuhan perinatal dan maternal yang lebih bermakna agar dapat menurunkan AKI dan AKB.

\section{DAFTAR RUJUKAN}

[1] Arikunto, S. (2006). Prosedur Penelitian Suatu Pendekatan Praktik. Jakarta : Rineka Cipta .

[2] Hidayat, A.A. (2010). Metode Penelitian Kebidanan dan Teknik Analisa Data. Jakarta : Salemba Medika.

[3] JNPK-KR. (2008). Pelatihann Klinik Asuhan Persalinan Normal. DEPKES RI: Jakarta

[4] Mubarok, I, dkk. (2007). Promosi Kesehatan. Yogyakarta : Graha Ilmu.

[5] Notoatmodjo, S. (2012). Metodologi Penelitian Kesehatan. Jakarta : Rineka Cipta.

[6] Nursalam. (2011). Konsep dan Penerapan Metodologi Penelitian Ilmu Keperawatan. Jakarta : Salemba Medika.

[7] Prasetyawati, A. (2011). Ilmu Kesehatan Masyarakat. Yogyakarta : Nuha Medika.

[8] Prawirohadjo, S. (2007). Ilmu Kebidanan. Jakarta : BPSP

[9] Kementrian kesehatan. Profil Kesehatan Indonesia 2012.

[10] Saifuddin, AB. (2006). Ilmu Kebidanan. Jakarta : BP-SP.

[11] Saifuddin, AB. (2009). Ilmu Kebidanan. Jakarta : BP-SP.

[12] Sugiono. (2006). Statistika Untuk Penelitian. Bandung : Alfabeta.

[13] Sulistyawati, A \& Nugraheny, E. (2010). Asuhan Kebidanan pada Ibu Bersalin. Jakarta : Salemba Medika.

[14] Survey Demografi dan Kesehatan Indonesia. (2012). Kementrian Kesehatan.

[15] Yulifah, R \& Yuswanto, T.J.A. (2009). Asuhan Kebidanan Komunitas. Jakarta : Salemba Medika. 